Artículo de investigación

Cuestiones de Filosofía

ISSN: 0123-5095

E-ISSN: 2389-9441

Vol. $3-\mathrm{N}^{\circ} 21$

Junio - diciembre, año 2017

pp. 19-41

\title{
El concepto de heterotopía en Michel Foucault
}

\author{
The concept of heterotopia in Michel Foucault
}

María Cristina Toro-Zambrano ${ }^{1}$

Colegio San Francisca Romana, Colombia

Recepción: 27 de abril del 2017

Evaluación: 15 de agosto del 2017

Aceptación: 3 de octubre del 2017

\footnotetext{
1 Filósofa de la Universidad de La Salle. Magíster en Filosofía Latinoamericana. Universidad Santo Tomás. E-mail: mkristor@gmail.com

El concepto de heterotopía en Michel Foucault,

María Cristina Toro-Zambrano - p. 19-41 


\title{
Resumen
}

El análisis del concepto de heterotopía, explicado por Michel Foucault en su conferencia "Los espacios otros", tiene importancia dentro del proyecto general de una historia crítica del pensamiento. Las heterotopías pertenecen a un tipo específico de espacio, que tiene dentro de sí poderes, fuerzas, ideas, regularidades o discontinuidades, se pueden clasificar según el tiempo o el lugar al que pertenecen y abren la posibilidad de crear nuevos espacios con sus propias lógicas.

Palabras clave: Acontecimiento; utopía; heterotopía; emplazamiento.

\begin{abstract}
The analysis of the concept of Heterotopia, explained by Michel Foucault in his lecture "The Other Spaces", is important within the general project of a critical history of thought. The heterotopies belong to a specific type of space, which have within themselves powers, forces, ideas, regularities or discontinuities, that can be classified according to the time or place to which they belong and open the possibility of creating new spaces with their own logics.
\end{abstract}

Keywords: Event; Utopia; Heterotopia; location 


\section{INTRODUCCIÓN}

La reflexión sobre "Des espaces autres" requiere, en primer lugar, una exposición del proyecto foucaultiano de una historia crítica del pensamiento, que constituye el marco general de todo el trabajo filosófico del pensador francés Michel Foucault, ya que, en palabras de su asistente en el Collage de France, François Ewald: "Si Foucault puede enmarcarse en la tradición filosófica, sería en la tradición crítica de Kant en la que se pudiera denominar de este modo" (Foucault, 1999c:363). Aquí es cuando adquiere sentido el análisis de ciertos tipos de espacios que surgen en el acontecer histórico, del cual, no obstante, Foucault pretende hacer crítica.

En el texto de 1984, Foucault por sí mismo, firmado por el autor bajo el seudónimo de Maurice Florence, Foucault inscribe su investigación en la línea del pensamiento crítico de Kant. Como lector que actualiza la crítica, se hace la pregunta, ¿qué es la filosofía moderna? Lo que equivale a decir, ¿qué es actualidad? (p. 72). Estas cuestiones le permiten plantearse la exclusión de lo que es irracional para la racionalidad occidental: el panóptico, la escuela de la ignorancia, la clínica, la sexualidad, etcétera. Así, el proyecto general de la investigación de Foucault es Una historia crítica del pensamiento y el concepto de heterotopía, horizonte desde el cual plantea el problema del espacio como parte importante para la reflexión contemporánea, ya que: "La época actual sería más bien quizá la época del espacio" (1999:431).

\section{La historia CRÍtica del PENSAMIENTo}

El trabajo de Foucault es un proyecto investigativo en continuo desarrollo, que construye una reflexión propia y diferente a la tradición filosófica y plantea otra manera de hacer filosofía. Los grandes problemas de la tradición filosófica o de la "historia general de las ideas" se pueden resumir, según Foucault, en las preguntas: ¿qué es saber?, ¿qué es poder?, ¿qué soy yo? y ¿cómo es posible saber, poder y ser de otra manera? (Deleuze, 1987:149). Estos cuestionamientos son abordados desde cuatro nociones fundamentales: acontecimiento, series, regularidades y condición de posibilidad (Foucault, 2005:54); es decir, si se va a abordar el saber, este debe tratarse como un acontecimiento que tiene un despliegue en un espacio determinado. Dichas preguntas se modifican e interrelacionan, y generando un desarrollo diferente e inconstante que depende de la configuración espacial, por lo cual, requiere de métodos diferentes a los usados por la tradición filosófica.

El concepto de heterotopía en Michel Foucault, 
Tomar estos problemas filosóficos como acontecimientos implica, en un primer momento, entenderlos como un conjunto de relaciones de fuerzas, que permiten entrelazar elementos de diferentes proveniencias y de heterogéneos contenidos históricos, sin depender necesariamente de la línea del tiempo. Estos elementos no son categorías fijas, eternas y constantes históricas, sino variables que coexisten en el acontecimiento. Ellos construyen su unidad en la medida en que se relacionan y dependen del juego de relaciones.

El acontecimiento se forma por las relaciones de fuerza que permiten a sus elementos tomar un lugar y un contenido espacial, según la relación de la que dependa. La conformación de varios elementos en red forma series y varias de ellas forman la estructura del acontecimiento en su totalidad. De ahí que cada serie con elementos propios esté ubicada, es decir, que tenga un espacio, un lugar de dispersión que, en definitiva, sea espacialidad con su propio lenguaje y sus propias fuerzas de poder. "Acontecimiento — entendiendo por tal no una decisión, un tratado, un reino o una batalla sino una relación de fuerzas que se invierten, un poder que se cosifica, un vocabulario recuperado (...)-" (Foucault, 1988:48).

Así como menciona Deleuze en su texto sobre Foucault, "la organización de las series constitutivas de la estructura supone una verdadera puesta en escena y exige en cada caso valoraciones precisas" (1987:586). La cadena de series forma una estructura, el acontecimiento es la estructura, se encarna en ella, es en ella en la que toma forma y lugar, en la que los elementos han de convertirse en objetos estructurales, es decir, en puntos sin los cuales no puede existir la estructura. Estos deben ser parte de ella, como un todo espacial.

Todos los elementos que conforman la estructura poseen un lugar y una posición importante que le da contenido y valor al todo; si cambia el lugar de posición de un elemento, sus relaciones modifican toda la serie y la estructura misma. Es autorreferente: si cambia la parte, cambia el todo; si la posición se modifica, el espacio estructural también. "La estructura (...) se define por la naturaleza de ciertos elementos atómicos que pretenden dar cuenta, al mismo tiempo, de la formación del todo y de la variación de sus partes" (Deleuze, 1987:571).

Cualquier problema filosófico supone una estructura con múltiples elementos que lo hacen posible y, sobre todo, implica un poder que lo regula. Sin embargo, el todo no se satisface con un orden, sino que busca emerger en la historia, mostrarse en ella. El porqué de su emergencia obedece a la 
necesidad del azar, a una lógica aleatoria (Foucault, 1988:54), aparentemente inocente de su aparición. La intervención del azar en la aparición histórica es el primer principio de análisis que Foucault proporciona a la investigación, el cual exige un acercamiento aparentemente espontáneo en el que el investigador solo debe mirar lo que la historia de los acontecimientos le manifiesta. Desde allí, la historia es entendida como el escenario de los acontecimientos, en donde deja ver las series con toda su potencia e información estructurada, su forma específica de ser y las condiciones bajo las cuales emerge su regularidad. La historia se convierte en el teatro de los acontecimientos filosóficos y en el lugar en donde estos habitan y se dispersan (Castro, 2004:17), por esto, toda investigación de cualquier acontecimiento será histórica.

Al acontecimiento no le basta con mostrarse en la historia, sino que busca imponer su estructura a lo más concreto y singular del mundo, de tal manera que las series se hagan visibles y triunfen como configuradoras de la realidad histórica. Esto ocurre de tal manera, de modo que, además de dispersarse, genera efectos en los cuerpos y en las singularidades, y espacios discursivos como instituciones, monumentos, arquitecturas, que reproducen en la materialidad las series y las reglas de pensamiento y de verdad. Es decir, todo lo que el mundo es, en tanto singularidad material, es efecto de algo ya estructurado; antes de su existencia ya estaban organizadas sus relaciones, su sentido, su identidad: "el acontecimiento no pertenece al orden de los cuerpos, y sin embargo no es inmaterial; es en el nivel de la materialidad, como cobra siempre efecto, que es efecto; tiene su sitio, y consiste en la relación, la coexistencia, la dispersión, la intersección, la acumulación, la selección de elementos materiales" (Foucault, 2005:57)

Hacer un análisis histórico sobre un acontecimiento filosófico es hacer una historia sobre lo singular, que visibilice su cambio, continuidad o fractura. La singularidad es la parte que refiere al todo, y el espacio son las configuraciones en la que esa singularidad habita, por tanto, es necesario partir de una singularidad especializada. De allí que Foucault haga una historia de la clínica (Historia de la locura), de la prisión (Vigilar y castigar), del cementerio (Espacios otros), de la historia del cuerpo (Historia de la sexualidad), del habla, (El orden del discurso); es decir, hace historia sobre distintos tipos de espacios arquitectónicos y discursivos. Pero, en cada una de ellas, toma singularidades muy específicas y concretas, desde las cuales se explica su historia y la gran historia en general: la historia del mundo moderno desde sus comienzos.

El concepto de heterotopía en Michel Foucault, 
No hay singularidad que no sea un espacio y que no remita a una multiplicidad de relaciones. Cosas, cuerpos, prácticas, discursos, se muestran en la historia como lo único válido según su transcurrir continuo, lo que garantiza una forma única de representación del mundo. Todo lo que esté por fuera de ello — dada su discontinuidad —, no pertenece a la historia universal, verdadera y real, sino que, por exclusión, está obligado a habitar la exterioridad.

En el marco de la historia crítica del pensamiento, el espacio es un concepto que está presente en el comienzo del acontecimiento, en su dispersión material y en su forma última de exterioridad. El acontecimiento, punto de partida de la investigación histórico-crítica, tiene un comienzo y los comienzos se ubican en lugares dinámicos que los hacen posibles (Foucault, 1988:29). Los comienzos son históricos y se oponen al origen, ya que no remiten a una esencia identitaria, sino que son conglomerados históricos, cuya diferencia intrínseca marca su procedencia, genera elementos dispersos que se acumulan y hace posible al acontecimiento. Así, pueden existir múltiples comienzos en un fragmento histórico.

Los comienzos son rupturas diferenciales en la historia discontinua y se levantan por debajo de la historia del origen (historia tradicional de las ideas). Por el contrario, los comienzos generan rupturas discontinuas que se localizan cuando emergen materialmente en los acontecimientos, es decir, cuando se muestran en la historia. La escogencia de estas singularidades se da precisamente porque ellos están ubicados en lugares extraños y porque cumplen con la condición de rarefacción, a saber, son parte de un lugar otro. Los lugares otros de los que habla Foucault son las utopías y las heterotopías, lugares diferentes al orden y a la regularidad de la aparente historia continua, homogénea, lineal, que se instala como sistema universal, eterno, unitario.

Los espacios mencionados son exclusiones de este sistema homogéneo, porque pertenecen a otras historias, a la historia de lo otro. Sin embargo, solo a través de esta se explica la historia general de las ideas, solo a través de lo excluido se entienden la regularidad, el sentido, la estructura y las reglas que tiene la historia tradicional. En una entrevista con J. K. Simon, Foucault lo explica así:

Me pareció interesante intentar comprender nuestra sociedad y nuestra civilización mediante sus sistemas de exclusión, sus formas de rechazo, de negación, a través de lo que no se quiere, a través de sus límites, del sentimiento de obligación que incita a suprimir un determinado número de cosas, 
de personas, de procesos a través, por tanto, de lo que se deja oculto bajo el manto del olvido, en fin, analizando los sistemas de represión-eliminación propios de la sociedad (Foucault, 1999:28).

En consecuencia, los problemas filosóficos que se instalan en esta historia tradicional de las ideas se estructuran para dispersarse en ella, de modo tal que forman el mundo, lo dibujan, lo moldean, según un marco epistemológico fijo, para gobernar los espacios, los lugares y todo lo que en ellos se relaciona. Lo anterior da origen a un modelo de vida, de acciones, de sujetos propios para habitar ese sistema, pero que a la vez excluye pensamientos, sujetos y espacios; todo lo que aborta el sistema está visible en el mundo. Es a partir de lo excluido que se entiende la estructura del todo al que pertenecen esos problemas, es decir, como el afuera de un adentro al que se auto refieren.

Hablar de espacios, dentro de esta otra forma de análisis, genera una diferencia intrínseca con respecto al modo tradicional de los problemas filosóficos, ya que, si bien toma los fragmentos - no los universales, que son los primeros en ser rechazados-, asimismo, toma la parte, que a su vez ha de ser la parte excluida, la parte diferente, la diferencia, no dentro del orden universal en un movimiento dialéctico, sino una total diferencia: una alteridad. Por último, hacer un trabajo espacial cambia y contradice el análisis temporal: "La utilización de términos espaciales presenta un cierto aire de antehistoria para todos aquellos que confunden la historia con las viejas formas de evolución, de la continuidad viviente, del desarrollo orgánico, del progreso de la conciencia o del proyecto de la existencia" (Foucault, 1999c:320).

Así, Foucault hace el análisis inverso, no se parte de la historia lineal para entender qué estructura tiene y excluye, sino que parte de las singularidades excluidas que están visibles y ubicadas espacialmente en lo más inmediato del mundo. Él parte de lo material, empieza a reconstruir lo que construyó, esa historia tradicional de las ideas, y se pregunta cómo se conformaron las relaciones, de dónde provienen sus elementos, por qué se organizaron las series homogéneas y bajo qué lógica se jerarquizaron y se invirtieron, cómo emergió en la historia una estructura regular, por qué se vuelven homogéneas y de qué manera se dio lugar a un sistema único y universal, que excluye a otros sistemas (1999c:364).

Foucault nos lanza a una nueva forma de trabajo, esta es Una historia crítica del pensamiento, que pone a la historia como aquel centro del cual es indispensable partir, un análisis histórico que muestre cómo se ha conformado 
aquello que se presenta de las cosas. Para el caso del espacio otro, la historia ha de mostrar el proceso y las relaciones que lo forman, pero siempre acompañado del ejercicio crítico, que pone en evidencia, con la duda continua, aquellas relaciones que hacen estipular, unificar y universalizar ciertas determinaciones espaciales, y que a su vez excluye otras.

La emergencia del comienzo se da en la emergencia del acontecimiento; de allí que este último sea algo actual, evidencie unas rupturas y abra universos paralelos al sistema regular del que deriva. Lo actual es precisamente lo impreciso de ese orden, es eso que se le escapa. La emergencia del comienzo designa "un lugar de entendimiento, un no-lugar, una pura distancia, en el cual los adversarios (las fuerzas) no pertenezcan al mismo espacio" (Foucault, 1988:38), sino que lo contradigan. Esa pura distancia es el espacio abierto que existe entre elementos, que proceden de lugares heterogéneos, y permite establecer el juego de relaciones. En esta pura distancia el espacio vacío se llena al recibir los elementos y soportar la caoticidad y fuerza del acontecimiento. Inicialmente, es un espacio en el que se dispersa también el contenido significativo de los elementos y en el que confluyen otros comienzos; es un espacio que sostiene en sí mismo todo el poder enunciativo y discursivo que llega a él, capaz de recibir el contenido procedente de los comienzos con toda su información genealógica.

En el comienzo se empiezan a estructurar las relaciones entre los elementos gracias a la distancia que existe entre las cosas; la movilidad permite acercamientos y lejanías y hace que se conformen series que harán posible la historia venidera. Así mismo, el espacio disperso y vacío permite la conformación de otros espacios estructurales, dentro de los cuales se gestarán otros lugares, que a su vez constituirán el acontecimiento. Se trata precisamente de lugares y sitios de un espacio propiamente estructural, es decir, topológico. El espacio topológico es pre-extensivo, es anterior a todo lo extenso, anterior al acontecimiento, a las cosas, las cuales solo aparecen en la medida en que ocupan un lugar, un sitio que las haga visibles; por ello, los lugares priman sobre quienes los ocupan. El espacio topológico está constituido por aproximaciones y por orden de vecindad entre elementos, que remiten a series relacionadas entre sí para hacer posible el espacio. Este espacio del comienzo, al estructurarse, se vuelve un espacio topológico, en el que la relación fija de sus elementos emerge en la historia y hace visible el lugar que ocupa cada elemento dentro de la estructura. Ese lugar ha de ser singular y material pero sin perder su relación con el todo. 
El modo en que los elementos se visibilizan en la historia es al mostrar su posición o lugar de ocupación dentro de la estructura a la que pertenecen, por ello, los elementos son cualificadores de lugares o de posiciones, todo depende de los lugares de la estructura, según el puesto que les corresponda dentro del orden topológico de vecindad (Deleuze, 1987:573). La visibilidad es espacial, por ello la superficie será una localización topológica que contiene las relaciones del comienzo. El comienzo es el espacio abierto y disperso que luego se organiza en un espacio topológico, que sigue en movimiento, y permite la conformación de más relaciones. Este espacio es la episteme.

El comienzo del acontecimiento se estructura con las oposiciones de sus fuerzas y sus diferencias; sus relaciones se organizan en series y ese espacio abierto y disperso empieza a evidenciar una carga de fuerzas que juegan unas con otras. Asimismo, este espacio más ordenado permite a los elementos tomar una posición en relación con los demás. Foucault ha denominado este espacio como episteme, el cual configura una estructura relacional cuya regularidad hace que se agrupen las relaciones y tomen posiciones más determinantes.

La episteme es un espacio de la estructura del acontecimiento con un criterio de posición, de la que dependen las series en un mismo conjunto, en el que significados, contenidos lingüísticos y juegos de poder hacen que la organización se dé al mismo tiempo con el espacio que ocupan. La episteme es por ello un espacio de dispersión, en el que convergen distintos elementos, cada uno de los cuales toma un lugar y se relaciona específicamente con otro de acuerdo a su posición. Así, pueden establecer, en una dirección, una relación de poder, lenguaje y saber o, inversamente, una relación de saber, lenguaje y poder, que modifican el sentido de la misma, dada la ubicación y el orden de las series. Por ello, la estructura se consolida cuando se entrelazan todos los elementos en un mismo sistema dinámico; para que funcione la episteme sin renunciar al movimiento y cambio al que está sujeto, se autorregula mediante reglas específicas que ella misma crea, es decir, su regularidad está dada por reglas que la organizan. Dichas reglas se imponen en lugares singulares y materiales que han conquistado las relaciones y series de la episteme, o sea, la episteme se materializa en espacios más singulares y en ellos reproduce las formas de las relaciones estructurales. Cada episteme instaura entonces un saber, unas reglas para ese saber, un discurso para ese saber, y crea espacios muy específicos y topológicamente localizables en donde deja ver ese conglomerado de información organizada. Dichos espacios singulares son

El concepto de heterotopía en Michel Foucault, 
resultado de la dispersión material; su materialidad es espacial y en ellos están los cuerpos, las cosas, las palabras, los gestos, las pasiones propias de cada episteme.

Se puede hablar entonces del espacio del lenguaje, del cuerpo, del saber, del poder; lo que implica un lugar material en el que se ha hecho efectiva la regularidad de la episteme. Esto explica la capacidad que tiene el acontecimiento para evidenciar su regularidad, de tal manera que todo funciona como un todo organizado, en el que se puede determinar cuáles son sus series predominantes y cuáles los elementos que tienen más protagonismo en la estructura, ya que se reflejan en espacios efectivos.

Es por esto que la episteme es un espacio de pensamiento en el que se dibuja el pensamiento, en el que topológicamente se repiten imágenes; de esta manera, signos que se auto refirieren a la estructura, se siguen relacionando indefinidamente, se siguen moviendo y visibilizando en espacios cada vez más singulares. A pesar de que en ella misma se establezcan límites y coerciones, esta tiene como característica ser un espacio inagotable. Las reglas de una episteme tienen un marco para hacerse efectivas, a saber, ciertos límites que dependen del campo que debe dominar la episteme. Ese marco es determinado por el dominio de la episteme, en el que solo se pueden hacer efectiva las reglas y las series de la misma.

El acontecimiento puede tener varias epistemes y cada una de ellas tiene espacios que localmente lo reproducen, ya sea para invertirlo o para repetirlo, es decir, conforman un solo espacio. Cada episteme tiene algo que le es propio y, aunque no están separadas unas de otras, todas siguen generando relaciones que permiten ser parte de otra episteme de modo diferente, como una gran red. Esto es lo especial o lo más singular de la episteme, lo que la hace comportarse de cierta manera, según lo que domine en ella y sus relaciones predominantes, aquellas series que, por su fuerza, se materializan y conquistan territorios singulares. Estos son los dominios de la episteme, es decir, espacios que dominan la episteme en un conjunto y hacen que ciertas relaciones dominen sobre otras y se hagan visibles en la materialidad.

Esos espacios que habitan los sujetos, que hacen parte de la relación con el mundo, son la forma efectiva de discursos, reglas y saberes que se articulan bajo un solo dominio de poder que los enlaza, son espacios que reproducen la relación sistemática de la episteme, espacios efectivos de verdades, de discursos, de pensamientos que generó el dominio. Los dominios son espacios 
que, en niveles más pequeños, reproducen esas relaciones estructuradas de la episteme. Si la episteme constituye los grandes espacios de la historia discontinua, los dominios son el modo en que esta busca ser efectiva en la materialidad o, inversamente, los dominios son el modo efectivo de la episteme.

A los dominios los rige el poder de unión, no es un orden estructural nuevo dentro de la episteme, sino el poder que circula como sangre en las series ya conformadas y las hace más importantes y más densas entre otras relaciones. De igual modo, hace que se impongan unas sobre otras y las superpone hasta llegar a la superficie, donde se materializan y se visibilizan en otros micro espacios. En cada uno de los dominios se encuentran otros espacios en los que se han hecho efectivas las relaciones, esos espacios son materialmente localizables como, por ejemplo, monumentos, gestos, cuerpos, arquitecturas, pinturas, textos, que visibilizan el dominio y a la vez expresan las relaciones de la episteme, que remiten a la información genealógica de la que proceden. En la historia discontinua se encuentran epistemes que han sido constitutivas de saberes, de poderes y de discursos, como la episteme clásica, la moderna y la actual. Cada una de ellas posee dominios propios y prácticas específicas que, aun en la actualidad, pueden leerse y cartografiarse.

Para Foucault, el tiempo que tiene cada episteme depende de la regularidad del tema que se trabaje, lo que traspasa periodos de tiempo que la historia lineal ha marcado. En la episteme clásica, por ejemplo, que abarca la clásica, el siglo XVII hasta inicios del siglo XIX, los espacios dependen de los dominios de orden y clasificación en un espacio ordenado cualitativa y cuantitativamente, que reconoce escalas, divisiones, bajo la lógica de una "economía del espacio" en un espacio real. Así, este es un espacio dividido de las urbes socialmente constituidas. De esta manera, en el siglo XVII hay un afán disciplinario por el urbanismo, distribución del espacio social de las urbes, según criterio clasificatorio propio de la biología, las ciencias naturales y la evolución.

Con la teoría helio-céntrica de Galileo, la concepción del espacio en el medioevo se localizaba en lugares físicos que representaban la jerarquía celeste, con lo cual se modificó y constituyó un espacio infinito y abierto, en el que las cosas que permanecían en quietud, ahora, eran cosas impulsadas por el movimiento, "el lugar de una cosa ya no era más que un punto en su movimiento" (Foucault, 1999c:432). A partir del siglo XVII, la importancia del espacio no es su localización sino su extensión, la extensión del espacio constituye el valor de los lugares que se puedan habitar. En la modernidad, 
el espacio cobra un valor científico y un interés propio en la geografía como medición y localización del espacio físico-natural, tomado por la teoría física. Esto también adquiere un interés a nivel social en la arquitectura, que se enunciaba en las formas arquitectónicas, construcción de iglesias, de estamentos públicos, la distribución de viviendas cerca o lejos de los centros políticos y religiosos, el lugar de los acantilados y demás estructuras que generaban los problemas de la ciudad.

La distribución del espacio se evidenciaba en lo social, campo en el cual se encontraban lugares de inscripción propios de estrategias de poder, o de tácticas de hábitat, que fueron generados por el saber arquitectónico del siglo XVII y XVII. Este saber se distanciaba de la física natural, de la geografía, ya que buscaba localizar el espacio social de tal manera que respondiera a un orden político. Esto hizo que el tema del espacio se trabajara científicamente y fuera el problema central de disciplinas nacientes del siglo XIX como el urbanismo, la arquitectura, la geografía política, la física teórica, la topología, las ciencias naturales, la geología, en las cuales, la historia del espacio encontró su desarrollo. Estos saberes obedecían a una estrategia de hábitat urbana, en la que el espacio debía ser útil y dividido para proporcionar una economía espacial que garantizara la fácil distribución mercantil de sus poderes específicos. En la episteme actual, el problema del espacio cobra mayor importancia, por lo cual, para Foucault, esta es la época del espacio, ya que dominios como la simultaneidad y yuxtaposición entre lejanías y cercanías y emplazamiento hacen del espacio el mayor determinante de las prácticas efectivas y de espacios relacionados en él.

A partir de la relación de emplazamientos, se dan las utopías y heterotopías; estos últimos tienen principios que le son propios para ser distinguidos en la historia. La episteme actual, que es la época propiamente del espacio, es el dominio propio del desplazamiento, de la simultaneidad, de la yuxtaposición entre cercanía y lejanía. En esta episteme, el espacio posee diferentes formas de ordenamiento y distribución, pues el espacio es propiamente "relación": es emplazamiento, que "se define por las relaciones de vecindad entre puntos o elementos; formalmente es posible describirlos como series, árboles, cuadrículas" (Foucault, 1999:432). El emplazamiento es relación que hace posible el espacio.

El espacio, entendido desde el emplazamiento, no es ya ni un lugar vacío que se llena o se distingue geográficamente, sino relación que se establece entre cuerpos, objetos y palabras, entre imágenes, discursos, sujetos y cuerpos, 
entre palabras y gestos, todos en una posibilidad infinita de relaciones y multiplicidad de emplazamientos posibles. El emplazamiento permite circular elementos, códigos e información de un dominio a otro y, a su vez, la clasificación y técnica de almacenamiento, según el dominio que se especifique, de la información de una relación a otra. En la actualidad, se vive en un lugar de relaciones que produce emplazamientos, que no se pueden describir bajo un solo dominio o relación, sino como relación de emplazamientos. Si la episteme actual es la época del espacio, este espacio se define por la relación de emplazamientos, es decir, por la relación entre relaciones organizadas serialmente, a la manera de un fractal. "Estamos en una época en que el espacio se nos da bajo la forma de relaciones de emplazamiento" (Foucault, 1999c:433) y existen tres tipos de emplazamientos que sobreviven y configuran la episteme actual, ellos son: el emplazamiento moderno o espacio interior; emplazamientos externos, o espacio exterior y emplazamientos virtuales, o espacio lógico-formal.

El primer emplazamiento es el moderno, o espacio interior, es el que predominó en la vida práctica, social y cotidiana de las nacientes ciudades, ya que sus relaciones públicas, culturales, privadas, laborales y comerciales implicaban arquitecturas, cuyos espacios físicos eran definitivos en la formación del sujeto moderno. Estos espacios que sobreviven aún codifican el mundo actual a través de sus monumentos, son espacios que todavía no han sido desacralizados porque ejercen prácticas específicas en la vida del ciudadano.

Y acaso también nuestra vida esta aun dominada por cierto número de oposiciones, que no sean tocadas, (...) oposiciones que admitimos como si estuvieran dadas: por ejemplo, entre el espacio privado y el espacio público, entre el espacio de la familia y el espacio social, entre el espacio cultural y el espacio útil, del ocio y el espacio del trabajo; todas estas oposiciones están animadas todavía por una sorda sacralización (Foucault, 1999:433).

Habitar dichos lugares reproducía y reproduce en la cotidianidad el saber público, privado, laboral o cultural en el que se está inmerso, como si fuera una experiencia esencial para el sujeto; un sujeto que habita espacios y es determinado por las normas internas, por los discursos, por las cosas que se hallan en ese espacio.

Estos emplazamientos, cuya variedad se da dentro de los espacios físicos, se auto refieren unos a otros a menor escala y repiten el mismo discurso, el mismo saber, la mismas normas y el mismo tipo de sujeto del gran sistema 
de poder que los rodea. A pesar de que es un emplazamiento variado, que implica varios lugares y elementos heterogéneos, la repetición y multiplicación se da sobre lo mismo pero dentro del orden lógico del sistema espacial, es decir, se amplían o simplifican las prácticas pero su forma no cambia, son isotópicas.

Estos espacios aún se visibilizan en las ciudades contemporáneas debido a la rigidez del sistema en el que se encuentran su discurso y poder, a causa de que su herencia preclásica, clásica o moderna se haya auto-regulado y siga reiterándose en la materialidad en forma de arquitectura religiosa, judicial, escolar, hospitalaria, carcelaria, así como en casas culturales o en obras de arte, textos o construcciones urbanas. Este emplazamiento moderno constituye espacios de la vida práctica, cotidiana y social que, a su vez, presentan múltiples relaciones, aunque auto-reguladamente. Este tipo de emplazamientos hace de la historia de lo mismo, un complejo impenetrable, ya que sus espacios están dispuestos de tal manera, para que el sujeto los habite, repita las normas y las inserte en sí mismo, para que constituya su propio ser y con ello afirme el poder y el pensamiento hegemónico que lo determina. El emplazamiento moderno crea lugares comunes, lugares internos, cerrados y organizados milimétricamente, para reproducir tautológicamente un discurso y un saber específico. Esta forma isotópica de los emplazamientos modernos llevó a la creación de los dispositivos de poder, que tienen la propiedad de clasificar minuciosamente los sujetos, así como se clasificaban los animales, según especie tipo y género. Además, cuida cada uno de los discursos e intensifica las prácticas de diferenciación y de enunciación sobre el sí mismo. Un ejemplo de lo anterior propuesto por Foucault es el panóptico.

El segundo tipo de emplazamiento es el virtual, este espacio es netamente lógico, no es físico, se basa en la simultaneidad del espacio sin importar las dimensiones y desvirtúa la posición de lejanía y cercanía entre los elementos, los disuelve y los distorsiona. Este tipo de espacio implica sujetos variables que aparecen y desaparecen según la relación que se establezca con un objeto igualmente móvil e inestable. En este emplazamiento es clara la relación de la tecnología en el mundo actual, el modo en que cambia inestablemente los objetos, según su posición, su velocidad; asimismo, es propio de la era tecnológica de la información y comunicación. "Así, lo que está más allá de lo 'físico' es lo 'lógico', lo 'virtual', y con ello, tal vez nos encontremos en el inicio de una 'episteme' a la que podría llamarse 'episteme virtual' y cuyo impacto en nuestras nociones y forma de vida, aún debe dilucidarse" 
(Albano, 2005:70). Este no es un espacio físico, los sujetos inmersos en ella no son constantes y son igualmente inmateriales. Al respecto, la línea de trabajo queda abierta y la problemática sigue creciendo en tanto que avanza la tecnología, la tecno ciencia, la biotecnología, etcétera.

El tercer tipo de emplazamiento es el externo, que constituye espacios capaces de establecer relaciones con todos los emplazamientos posibles, lo cuales utiliza pero, a la vez, contradice, con lo que permite que se conecten con otros emplazamientos sean modernos, virtuales u otros. De este modo, hacen que el sentido de sus elementos internos se invierta y se modifiquen continuamente. De los emplazamientos que existen en la historia discontinua, los externos en oposición a los internos son, quizá, los que más se acercan a la dinámica del acontecimiento, ya que pueden configurar, en sus múltiples relaciones, otros emplazamientos, sin importar la posición en que se encuentren sus relaciones primarias. Las relaciones de estos emplazamientos externos son indeterminables porque están siempre en apertura y cierre, por ello, son espacios otros, inclasificables. Los externos son emplazamientos que se conforman con las relaciones de otros y juegan a conectarlas y a fracturarlas, así, las moldean hasta conformar una forma especial, pero diferente. Esto le da otro sentido a la organización interna y multiplica la posibilidad de tener otras formas, lo que implica discurso otro, cosas otras, un sujeto otro.

Los emplazamientos externos no son ni de un afuera ni de un adentro, son exterioridad e interioridad a la vez, se ubican en un adentro y fuera de (sistema, episteme o dominio); es decir, son auto referentes a su estructura pero, a la vez, difieren de ella, se hallan en un tiempo presente y en un presente progresivo a la vez: son emplazamientos imprecisos, porque están sujetos a ser posibilidad de ser lo que aún no son. Estos espacios son heterogéneos, contienen elementos de un sistema fijo de relaciones, pero también crean y recrean nuevas relaciones con el exterior. Ellos no se ubican en un futuro, como resultado del proceso de un sistema regular, ni en un pasado, como anteriores a la formación del mismo, sino que son actualidad de las estructuras. Lo actual es precisamente aquel lugar-umbral, límite que marca el adentro o el afuera de un sistema, pero cuya tierra de nadie se da por exceso del todo, exceso de relaciones estructuradas, de poder, de prácticas, de discursos. Inversamente, se pueden dar por carencia de todo lo que existe y carencia de exceso de relaciones. Son actualidad de las series del sistema y, precisamente por ello, son espacios que inquietan o cuestionan todos los emplazamientos modernos y, en general, de la historia de lo mismo. Tanto por carencia como 
por exceso se originan los emplazamientos externos, , bien sea por exceso de relaciones materializadas, ; como por carencia de relaciones materializadas, se dan espacios que busquen realizarlas.

Mientras que unos emplazamientos se dan por el desborde de lo concreto otros permiten lo abstracto. Ambas formas son posibilidad de un lugar otro; lugar que se relaciona con el exceso o con la carencia de su sistema, dominio o episteme, para modificar el sentido las series, su significado, el curso de las relaciones, las leyes que las rigen. Incluso el sujeto que se encuentra en dichos emplazamientos se modifica, en tanto que depende de un espacio de posibilidad de ser de otro modo. Estos espacios se rigen por un orden aparente de la estructura a la que pertenecen pero gozan de la imprecisión del orden impuesto y, por tanto, de la posibilidad de "ficcionar lo que aún no existe" (García, 2006:65) como, por ejemplo, el espacio de la literatura.

Los emplazamientos externos se refieren a lugares que se habitan desde lo material o lo inmaterial, es decir, desde lo más concreto y tangible o desde lo más abstracto, imaginario e intangible, pero en los cuales, al estar en cualquiera de los extremos, se suspenden las relaciones internas del emplazamiento. "Entre todos los emplazamiento algunos tienen la curiosa propiedad de estar en relación con todos los emplazamientos pero de un modo tal que suspende, neutraliza o invierte el conjunto de relaciones que se encuentran por sí mismos, reflejados o reflexionados"(Foucault, 1999:434). Estos emplazamientos se ubican siempre en el límite de una episteme, o de un dominio, en la puerta o borde de un sistema autorregulado, sus relaciones se encuentran al margen de todas las series estructuradas, son precisamente aquellas líneas que se encuentran en la periferia y cuyas configuraciones discursivas, prácticas y de pensamiento se convierten en "otras" en relación con las del sistema al que pertenecen, lo que también se refleja en lugares periféricos, lugares ajenos, extraños o diferentes.

Existen dos emplazamientos externos que efectúan este tipo de relaciones y que contradicen los demás emplazamientos; estos son las utopías y las heterotopías. Los primeros se caracterizan por crear espacios irreales en los que la perfección tenga su existencia, pero tienen la característica de no ser espacios físicos localizables, son no-lugares de algo no-realizado, pero que posibilitan la construcción del presente como horizonte de sentido. "Las utopías son los emplazamientos sin lugar real, estas utopías son espacios fundamental y esencialmente irreales" (Foucault, 1999:434). 
Los emplazamientos utópicos son lugares que están más allá de todos los lugares existentes en el mundo material, "son lugares sin lugar" (Foucault, 1999:435), ya que proporcionan la esperanza o confort artificial frente a los lugares físicos, que dependen de relaciones sistémicas. Las utopías instauran una lejanía anhelada que invita al abandono de sí mismo, al viaje cuyo rumbo promete condiciones de existencia diferentes a las del mundo real.

En las utopías convergen la máxima felicidad, la belleza, el sin tiempo y la sublimación de todas las cosas reales que perfeccionan al ser humano. Este tipo de emplazamiento se da por carencia de lo que existe en el mundo físico y es, por supuesto, posibilidad de todo lo inexistente. Así, lugares como el cielo, el sueño, el paraíso, el jardín de las delicias, la arcadia añorada, neutralizan la realidad e incrementan todos los anhelos y las posibilidades de acercarse a ese otro lugar, al cual no hay acceso en el mundo habitual. De algún modo u otro, toda sociedad en todo tiempo ha creado emplazamientos utópicos y un nuevo orden, aunque sea en la lejanía, con elementos extraordinarios, con acciones imposible de realizar: ciegos encontrando la tierra de la visión, morada de Dios y muertos bendecidos, árboles, frutos y animales sagrados, paraíso con serpientes que caminan y hablan, espejos que se cruzan y cartas de póker y conejos que bailan y cantan, o simplemente singularidades que habitan la memoria: recuerdos.

Estas utopías permiten que la subjetividad se construya a partir de lo que ofrece el mundo exterior, con todo su poder de afirmación en la cultura, en el lenguaje; es decir, en forma de comedia, que tome los elementos que configuran la cultura y los invierta, irónicamente, en la formación de un nuevo personaje que está en el punto máximo de las fuerzas pero que, a la vez, las revierte con ironía y se recrearse a sí mismo. De esto son testigo y promotor la literatura y el arte. Las utopías son emplazamientos sin una localización física y ejercen una analogía directa o inversamente proporcional con la sociedad, o sea, son espacios que crean nuevas condiciones para el presente.

"En el espejo, por ejemplo, me veo donde no estoy, en un espacio irreal que se abre virtualmente detrás de la superficie, estoy allá, allá donde no estoy, especie de sombra que me devuelve mi propia visibilidad, que me permite mirarme allá donde estoy ausente" (1999c:435). Para Foucault, el espejo es ese otro lugar propio de la utopía, es un lugar sin lugar, que muestra lo que no es, pero refleja lo que se quiere ser, y posibilita habitar ese lugar que no es real pero que configura el mundo físico, un lugar cuyo efecto es irreal y permite ser de otra manera más allá de lo que le presenta el mundo habitual y cotidiano, al cual se está sujeto.

El concepto de heterotopía en Michel Foucault, 
En oposición, las heterotopías son emplazamientos efectivos, utopías realizadas que se materializan, pero están por fuera de todos los lugares, no pertenecen al conjunto de los demás espacios físicos, están por fuera de todos los lugares y pueden ser localizables; son lugares otros, inclasificables entre todos los lugares porque su configuración escapa a espacios de poder, de saberes hegemónicos, de discursos organizados; son lugares que se dan por sí solos pero que se valen de lugares estructurados. Las heterotopías se forman con relaciones fracturadas de un sistema, por ello interrelacionan elementos que dentro de él serían imposibles de conectar, crean puentes entre una estructura y otra y hacen que sus relaciones constitutivas varíen, cambien y se contradigan. La heterotopía tiene lugar precisamente en el límite que ha excluido cualquier sistema o estructura regular, pero tiene la especialidad de tomar relaciones y elementos del sistema del cual fue excluido.

Hay lugares, lugares efectivos, lugares que están diseñados en la institución de la sociedad, que son una especie de contra emplazamiento, una especie de utopías efectivamente realizadas, en las cuales los emplazamientos reales, todos los emplazamientos reales que es posible encontrar dentro de la cultura, están a la vez representados, impugnados e invertidos; son una especie de lugares que están fuera de todos los lugares, aunque resulten efectivamente localizables. Ya que son absolutamente distintos a todos los demás emplazamientos que ellos reflejan y de los que hablan, estos lugares, en oposición a las utopías, serán llamados heterotopías (Foucault, 1999c:435).

Las heterotopías están por fuera de todos los lugares, y estos se convierten en lugares "impunes" dentro del mundo material, es decir, son topológicamente localizables, pero muestran de modo diferente las configuraciones de un dominio o episteme. Además, estos constituyen posibilidades de ser, de habitar el mundo, de hablar sobre el mundo; tienen sus propios principios para ser consideradas como espacios otros. El primero de ellos trata de heterotopías de crisis y de desviación de algunas estructuras, catalogadas así dentro del sistema por estar por fuera de ellos. Estas últimas se dan en lugares propios para individuos que generan crisis en las sociedades, sea cual sea la episteme de la cual dependan, aquellas que por exceso de leyes y códigos normativos están por fuera de la norma y se comportan críticamente frente a esta aunque deriven de ella. Por eso, cada estructura autorregulada excluirá cualquier comportamiento que visibilice un cambio con respecto a la sociedad, que esté en contra de los parámetros de normalidad. Para este tipo de casos diferentes, cada estructura crea espacios para ocultar o resguardar eso que altera su orden y pone en riesgo su estabilidad. 
Estas heterotopías de desviación se conforman a partir de espacios que vivieron crisis sociales y en los que se albergaron personas catalogadas como "desviadas" o tuvieron lugar circunstancias "anormales" según un tipo de pensamiento hegemónico; por ejemplo, las dictaminadas por el pensamiento clínico y judicial, el uno frente a los llamados "locos" y el otro frente a los "inadaptados sociales". Estas marcas de la exclusión y los espacios en los que se ubicaron esas personas o circunstancias se hacen visibles como monumentos, retratos, archivos, etcétera, que visibilizan eso que de diferente tiene cada episteme. Un ejemplo de estas heterotopías de desviación, que Foucault encuentra y analiza, son la clínica, la escuela militar y las escuelas educativas.

Así, lugares sagrados privilegiados o reservados, prohibidos por su condición sacra, lugares propios para la iniciación de roles sociales, cambios biológicos, pueden encontrarse en situaciones de crisis, que hacen de estas heterotopías lugares privilegiados, aunque estén por fuera de la estructura a la que pertenecen. De la misma manera, los adolescentes con sus cambios hormonales y sus nuevos roles se convierten en protagonistas y habitantes de dichas heterotopías. La condición de novia, de mujeres embarazadas, de ancianos, de leprosos, de enfermos, de mujeres menstruando, etcétera, configuran los personajes de estos espacios. La historia modifica el vocabulario para definir las mismas conductas de crisis en la sociedad, por ello, las heterotopías de desviación sustituyen a las heterotopías de crisis y ubican a los individuos, considerados como desviados con respecto a la norma común y exigida. Estas buscan la mejora de las posibles crisis, ya consideradas como crisis; tal es el caso de las casas de retiros, clínicas psiquiátricas, geriátricos y prisiones. Asimismo, crean espacios propios para resguardar esa crisis que desean excluir del sistema regular. Estas son generadas por los sistemas para evitar que el desorden de casos especiales habite el mismo espacio normatizado.

El segundo principio abarca las heterotopías de funcionamiento variable o cambiante, cuyos espacios sufren transformaciones, pasan a ser lugares impactantes, propios de la cultura a ser relegados según va cambiando el discurso sobre ese espacio determinado. Son heterotopías que en un momento fueron espacios importantes para la vida de un grupo humano, ya fuese por su sentido material o espiritual, político, militar, pero que, en la medida en que cambiaba la estructura de la que dependían, se modificaban, se convertían en lugares relegados u olvidados y constituían la negación de un pueblo. 
Para Foucault, una heterotopía propiamente variable es el cementerio cuya historia hizo que este espacio fuera variado y cuyo sentido lo haya hecho menos importante (Foucault, 1999c:436).

El tercer principio de las heterotopías corresponde a heterotopías de contradicción o espacios contradictorios. Las heterotopías tienen el poder de yuxtaponer en un solo lugar físico varios espacios que sean diferentes entre sí, de tal manera que formen un microcosmos en su interior, un espacio con otros posibles lugares, sean físicos o imaginarios. Así, por ejemplo, el cine, el teatro, las salas de concierto y parques de diversiones hacen que su espacio abra las puertas para otros lugares diferentes, en los que se está físicamente, pero cuyas escenas proporcionan otros lugares en el teatro hay un mismo escenario pero a la vez posibles lugares diferentes: mar, cielo, desierto, casas, habitaciones, el sueño, cada uno de ellos con emplazamientos puntuales que hacen que se modifiquen todas las relaciones que configuran el espacio físico, mediante objetos, colores, formas, palabras sonidos, que permiten que el espacio cambie. Esto hace que los múltiples lugares sean contradictorios con el lugar físico y, a su vez, con el lugar que los rodea, en el cual están localizados. Foucault nombra, entre estas heterotopías, los jardines persas y sus alfombras, que en su estructura espacial permiten entrar a otros espacios sagrados, que también remiten a las cuatro partes del mundo.

El cuarto principio se refiere a las heterocronías y heterotopías del tiempo. Las primeras tienen que ver con heterotopías que reflejan la ruptura del tiempo de los hombres con respecto al tiempo tradicional. Las heterotopías crónicas son lugares que precisamente están prefijados temporalmente, que son más efímeros y pasajeros, tiempos que se marcan según el espacio de duración; así, por ejemplo, el carnaval, la fiesta, las vacaciones, encuentran su valor solo en un tiempo que se determina para ellos.

Las heterotopías-museos organizan infinitamente el tiempo en un espacio determinado, es decir, acumulan el tiempo, lo archivan, lo fichan. Estas son heterotopías propias de la modernidad. Las heterotopías de tiempo son un lugar no lugar, que tiene un tiempo otro, un tiempo-notiempo. El tiempo es aquí un modo de ubicación dentro de muchos otros lugares. El tiempo se espacializa y así da lugar a un tiempo diferente y a un espacio que acumula al tiempo; el tiempo se detiene y no cambia de lugar.

Hay heterotopías del tiempo, o sea, un lugar no lugar, que tiene un tiempo otro, un tiempo-notiempo, en el cual, el tiempo es un modo de ubicación 
dentro de muchos otros lugares. El tiempo se especializa, así da lugar a un "tiempo otro", como en el caso de las bibliotecas y museos, donde el tiempo se acumula en un espacio, se detiene y no cambia de posición o, por el contrario, se dispersa en un espacio en el que el tiempo disperso parece no acabarse, es acumulativo hasta el infinito, no tiene reloj, o cuyo reloj y medida están dados por el espacio heterotópico en que está inmerso. Sin embargo, hay otro espacio que expande el tiempo, lo dispersa, no lo puede abarcar porque le es inconmensurable. Estas heterotopías pueden ser fiestas, celebraciones, centros vacacionales, centros comerciales, en donde el tiempo parece no acabarse; aquí también hay un tiempo otro.

El quinto principio es la apertura y cierre de los espacios, los cuales se encuentran aislados de todos los demás lugares pero pueden ser penetrables, ya que superponen un sistema de reglas, ritos y prácticas, cuyas condiciones muy específicas implican un comportamiento especial para entrar en ellos, como en el caso de las iglesias, partidos políticos y grupos juveniles, entre otros.

El último principio de las heterotopías es lo real-irreal de los espacios que se encuentran entre dos polos extremos y opuestos y se orientan a crear un espacio ilusorio pero real, en el punto medio, en el punto cero entre dos grandes sistemas de los que son el restante, el afuera de ellos.

Estas heterotopías tienen espacios definidos y configurados de tal manera que escapan a todo control y normatividad, por su apertura infinita. Para Foucault, las heterotopías son por excelencia el viaje, cuyo navío hace una travesía; el viaje es la exploración a nuevas tierras lejanas y, por supuesto, cumple con el requisito de abrir posibilidades de existencia diferentes y de pensar y ser de otro modo.

\section{MÁs ALLÁ del CONCEPTO de hETEROTOPÍA}

Si bien el concepto de heterotopía, se inscribe en el análisis de las relaciones de poder, de la historia y de los espacios otros, también puede entenderse como un concepto para el tratamiento estético en la creación de líneas de fuga, en espacios como la literatura, el arte y la arquitectura, por mencionar algunos. Estos, si bien muestran sus relaciones internas de poder, crean a su vez espacios diferentes, que hacen crítica a otros espacios de control y de dominación discursiva que, en muchos casos, rompen con la imposición del tiempo o de una episteme. Esa posibilidad de espacios otros en el mundo 
contemporáneo puede ser abordada desde el concepto de heterotopía, al ser entendida como una caja de herramientas (Foucault, 1994:110), que pueda usarse para otros espacios emergentes, otras realidades más allá de lo propiamente desarrollado por Foucault. Lo anterior, dado que, como el mismo autor referencia, "la época actual sería más bien la época del espacio" (Foucault, 1999:431). Un ejemplo del uso estético del concepto sería ver como heterotopía la obra literaria Farabeuf o crónica de un instante, del escritor mexicano Salvador Elizondo, y analizar allí los demás espacios no convencionales a los que la misma obra remite y que a su vez son solo un instante, cuya escritura no lineal permite crear espacios dentro de los espacios de la misma historia (Toro, 2008).

El análisis de la heterotopía o la heterotopología generan una manera distinta de entender el mundo actual y proponen un análisis más allá del ámbito académico y filosófico, que abre una línea de investigación interdisciplinar y sirve como método o actitud crítica frente al campo histórico, social, artístico, existencial, científico, etcétera. De allí que la heterotopía constituya un recurso actual de la crítica, como dice Vattimo:

Una crítica - crítica es aquella que pone en juego incluso su propio proyecto existencial mientras busca comprender su objeto (...) porque es cada vez más inidentificable con su capacidad de abrir infinitos horizontes de ecos y referencias (...). Propongo llamar a esta capacidad "heterotopía" en lugar de la utopía predicada por Bloch y por la escuela de Frankfurt. Filósofos como Foucault o el Deleuze de Mil Mesetas parecen ser testigos de un mismo movimiento en filosofía en cuanto a la práctica de la crítica (...) (Vattimo, 1999:6).

Un ejemplo del uso crítico del concepto de heterotopía, para analizar heterotopías actuales, es el realizado por el curador de arte belga, Christophe Bruchansky, quien en su artículo, "The Hetetotopia of Disney World" (2010), encuentra que Disneylandia es simultáneamente un espacio utópico y heterotópico, que representa e inventa la sociedad de consumo occidental. Es así, como el concepto de heterotopía permite abordar, desde una reflexión filosófica, estética o simplemente crítica, los espacios otros que están en nuestro mundo inmediato y actual, bien sea porque se han transformado con la historia, han dejado de ser algo para convertirse en otros, para reflejar un saber, un discurso o para ser reflejo de lo que nos constituye como sujetos. 


\section{REFERENCIAS}

Albano, S. (2005). Michel Foucault. Glosario de aplicaciones. Buenos Aires: Quadrata.

Bruchansky, C. (2010). The Heterotopia of Disney World. Issue 77. En https://philosophynow.org/issues/77/The_Heterotopia_of_Disney_World. Recuperado: julio de 2016.

Castro, E. (2004). El vocabulario de Michel Foucault. Buenos aires: Universidad Nacional de Quilmes.

Deleuze, G. (1987). Foucault. Barcelona: Paidós.

Foucault, M. (1988). Nietzsche: La genealogía y la historia. Valencia: Pre-textos

----- (1999). ¿Qué es un autor? En Obras esenciales. vol. I. Barcelona: Paidós.

----- (1999). Foucault por sí mismo. Obras esenciales. vol. III. Barcelona: Paidós.

----- (1999). Espacios diferentes. En: Obras esenciales, Vol. III, Barcelona: Paidós, 431-441.

------ (1999). Conversaciones con Michel Foucault. Entrevista con J. K Simon. En Obras Esenciales. vol. II. Barcelona: Paidós.

------ (2005). El orden del discurso. Barcelona: Tusquest.

----- (2003). Sobre la Ilustración. Madrid: Tecnos.

Vattimo, G. (1999). Crítica - estructuralismo - hermenéutica - heterotopía. El estructuralismo y el destino de la crítica. En Insomnia. n. ${ }^{\circ} 85$. Montevideo. http://www.henciclopedia.org.uy/autores/Vattimo/Vattimo1.htm Recuperado 15 de septiembre de 2017.

Toro, María Cristina.(2008). Laheterotopíaen Michel Foucault como concepto estético. http://repository.lasalle.edu.co/bitstream/handle/10185/13499/ T30.08\%20T634h.pdf; jsessionid=32B72959075FA7C29F9F86C1F044E1FE?sequence=1 Recuperado 15 de septiembre de 2017.

El concepto de heterotopía en Michel Foucault, 